DOI 10.15593/2409-5125/2018.02.07

УДК 625.89:628.544

\author{
Е.А. Пичугин ${ }^{1}$, Б.Е. Шенфельд ${ }^{1}$, А.А. Кетов 2 \\ 1Уральский государственный научно-исследовательский институт \\ региональных экологических проблем \\ 2Пермский государственный национальный исследовательский университет \\ КОМПЛЕКСНАЯ ОЦЕНКА ЭКОЛОГИЧНОСТИ \\ И КАЧЕСТВА ТЕХНОЛОГИЙ СООРУЖЕНИЯ ЗЕМЛЯНОГО ПОЛОТНА \\ АВТОДОРОГ С ИСПОЛЬЗОВАНИЕМ ШЛАМОПЕСЧАНОЙ \\ СМЕСИ - ПРОДУКТА УТИЛИЗАЦИИ ОТХОДОВ
}

\begin{abstract}
При бурении нефтегазовых скважин образуются буровые шламы - токсичные отходы бурения, преимущественно размещаемые в шламовых амбарах, которые оказывают негативное воздействие на литосферу. Воздействие происходит вследствие вывода земель из оборота, вырубки деревьев и кустарников, уничтожения надпочвенного покрова, недостаточной гидроизоляции амбаров при их строительстве и эксплуатации, использовании не отвечающих требованиям защиты окружающей среды технологий проведения рекультивационных работ. Перспективным направлением утилизации буровых шламов является утилизация путем создания на их основе строительных материалов, не оказывающих негативного воздействия на окружающую среду и пригодных для использования наряду с традиционными. С использованием методики комплексной оценки экологичности и качества природоохранных технологий произведена оценка технологий сооружения земляного полотна автомобильных дорог, в том числе с использованием шламопесчаных смесей на основе отходов бурения нефти и газа. Формируемый в соответствии с методикой индекс IEQ характеризует экологичность и качество технологии. Для проведения оценки построена модель, которая позволяет оценить природоохранные технологии по геоэкологическим, технологическим и эксплуатационным аспектам. Для оценки каждого аспекта был использован интегральный метод, заключающийся в том, что технологический процесс и техногенное воздействие рассматриваются в рамках балльной шкалы. Балльная оценка формировалась на основе экспертных оценок. По каждому аспекту показаны достоинства и недостатки представленных природоохранных технологий. Экспертами выбраны весовые коэффициенты для оценки различных аспектов и показателей, проведена оценка показателей для сравниваемых технологий, на основе чего рассчитан индекс экологичности и качества технологий. На основании проведенной экспертной комплексной оценки показано, что по совокупности геоэкологических,
\end{abstract}

Пичугин Е.А., Шенфельд Б.Е., Кетов А.А. Комплексная оценка экологичности и качества технологий сооружения земляного полотна автодорог с использованием шламопесчаной смеси продукта утилизации отходов // Вестник Пермского национального исследовательского политехнического университета. Прикладная экология. Урбанистика. - 2018. - № 2. - С. 86-97. DOI: $10.15593 / 2409-5125 / 2018.02 .07$

Pichugin E.A., Shenfeld B.E., Ketov A.A. Comprehensive assessment of environmental compatibility and quality of road bed construction with the use of sludge-sand mixture - the product of waste recycling. PNRPU. Applied ecology. Urban development. 2018. No. 2. Pp. 86-97. DOI: $10.15593 / 2409-5125 / 2018.02 .07$ 
технологических и эксплуатационных аспектов технология сооружения земляного полотна автодорог с использованием шламопесчаных смесей не уступает традиционной.

Ключевые слова: земляное полотно, утилизация отходов, буровой шлам, шламопесчаная смесь, оценка экологичности и качества.

В настоящее время для возведения земляного полотна автомобильных дорог используют в соответствии с требованиями СНиП 3.06.03-85 и ВСН 84-89 различные виды грунтов, в том числе пески, супеси и суглинки. Природный песок, имеющий оптимальные физико-механические свойства и низкую стоимость, получил широкое распространение в качестве дорожно-строительного материала. В то же время при добыче песка происходит нарушение ландшафтов (образование карьеров), загрязнение атмосферного воздуха (пыление), нарушение и загрязнение водных объектов при добыче речного песка.

Частичной заменой песка в дорожном строительстве могут являться материалы, полученные путем утилизации промышленных отходов, которых накоплено огромное количество.

При бурении нефтегазовых скважин образуются буровые шламы токсичные отходы бурения, преимущественно размещаемые в шламовых амбарах, которые оказывают негативное воздействие на литосферу.

Буровой шлам - водная суспензия, твердая часть которой состоит из продуктов разрушения горных пород забоя и стенок скважины, продуктов истирания бурового снаряда и обсадных труб, глинистых минералов (при промывке глинистым раствором) [1].

Основными компонентами, входящими в состав буровых шламов, являются породообразующие компоненты почв (оксид кремния, оксид алюминия и др.). Наиболее значимыми загрязняющими веществами, входящими в состав буровых шламов и определяющими их токсические свойства, являются растворимые соли, которые попадают в шлам из буровых растворов. Для обеспечения стабильности дисперсной фазы, а также снижения вязкости в буровой раствор могут вводиться хлорид калия и хлорид натрия [2]. Содержание тяжелых металлов, нефтепродуктов в буровых шламах незначительно превышает установленные ПДК (ОДК) данных веществ в почве. Влажность буровых шламов изменяется в достаточно большом диапазоне (от 37,3 до $88,1 \%$ ). Тип буровых шламов по разновидности глинистых грунтов - тяжелые, легкие текучие глины, суглинки.

Воздействие буровых шламов на окружающую среду происходит вследствие вывода земель из оборота, вырубки деревьев и кустарников, уничтожения надпочвенного покрова, недостаточной гидроизоляции амбаров при их строительстве и эксплуатации, использовании не отвечающих требованиям 
защиты окружающей среды технологий проведения рекультивационных работ. Это приводит к загрязнению экосистем, изменению литологического состава, температурного и влажностного режима подстилающих грунтов.

В настоящее время известно достаточно много способов и технологических приемов, направленных на обезвреживание, утилизацию отходов бурения. В частности, существуют методы и технологии термического обезвреживания буровых отходов $[3,4]$, физические методы утилизации буровых отходов (закачка в глубокозалегающие подземные горизонты) [5-7], технологии, основанные на добавлении связующих (отверждение, гидрофобизация, капсулирование) $[8,9]$, технологии и методы, основанные на биодеструкции загрязняющих компонентов буровых шламов с помощью микроорганизмов (биоремедиация) $[10,11]$ и др.

Перспективным направлением утилизации буровых шламов является утилизация путем создания на их основе строительных материалов, не оказывающих негативного воздействия на окружающую среду и пригодных для использования наряду с традиционными.

На территории Российской Федерации применяются технологии утилизации буровых шламов с получением строительных материалов на их основе. Перечень выданных с 2011 по 2017 г. положительных заключений государственной экологической экспертизы на проекты новой техники и технологии по утилизации буровых отходов с получением и применением строительных материалов на их основе по данным сайта Федеральной службы по надзору в сфере природопользования (http://rpn.gov.ru/node/654):

- Проект технической документации на «Новую технологию использования отходов от добычи нефти и газа с использованием «Техногрунт-S», пригодного в качестве инертного строительного материала и техногенного почвогрунта» / ООО «ЭкологияНефтьСервис»: утв. приказом Росприроднадзора по Пермскому краю от 17.05.2013 № 549.

- Проект технической документации на технологию «Обезвреживание отходов бурения с получением строительного материала» / ООО «Сервисный центр СБМ»: утв. приказом Росприроднадзора от 11.02.2015 № 104.

- Проект технической документации на новую технологию «Использование бурового шлама для производства грунта техногенного» / АНО «Экотерра»: утв. приказом Росприроднадзора от 29.04.2015 № 366.

- Проект технической документации «Новая технология изготовления рекультивационных смесей, пригодных для рекультивации нарушенных земель и подсыпки в нижние слои дорожного покрытия, получаемых при утилизации буровых шламов» / ЗАО «Нефтьстройинвест»: утв. приказом Росприроднадзора от 11.11.2015 № 901. 
- Технологический регламент по приготовлению и применению грунтов строительных на основе бурового шлама / ФГБОУ ВПО «Тюменский государственный университет»: утв. приказом Росприроднадзора по Тюменской области от 17.04.2015 № 269-э.

Результатом выполненного нами комплекса исследований [10-15] явилась разработка экологически безопасной технологии утилизации буровых шламов с получением шламопесчаных смесей - дорожностроительного материала, предназначенного для возведения земляного полотна автодорог. Экспериментальные исследования показали, что изготавливаемые с использованием буровых шламов шламопесчаные смеси по своим экологическим характеристикам соответствуют продукции, не оказывающей негативного воздействия на окружающую среду, а их физико-механические и деформационные характеристики отвечают требованиям СП 50-101-2004 и СНиП 2.02.01-83, предъявляемым к дорожностроительным материалам. Разработана технологическая схема производства шламопесчаных дорожно-строительных смесей для подсыпки внутрипромысловых дорог в условиях Западной Сибири [12].

Целью настоящей работы является комплексная оценка экологичности и качества технологий сооружения земляного полотна автодорог с использованием традиционного материала - природного песка (технология № 1) и шламопесчаной смеси, изготовленной путем утилизации буровых шламов по экологически безопасной технологии (технология № 2). Для оценки была использована разработанная Т.С. Титовой [18] методика комплексной оценки экологичности и качества технологий, в соответствии с которой формируется индекс IEQ, характеризующий экологичность и качество технологии. Оценка производилась путем сравнения технологий получения дорожностроительных материалов по геоэкологическим, технологическим и эксплуатационным аспектам [19]. На рисунке представлена разработанная модель комплексной оценки экологичности и качества технологий.

Для оценки каждого аспекта был использован интегральный метод, заключающийся в том, что технологический процесс и техногенное воздействие рассматриваются в рамках балльной шкалы. Балльная оценка формируется на основе экспертных оценок в рамках единой шкалы в диапазоне от 0 до 1.

Для экспертной оценки нами был привлечен коллектив специалистов в количестве 10 человек (доктора и кандидаты наук - специалисты в области дорожного строительства, охраны окружающей среды, геоэкологии). Экспертами выбраны весовые коэффициенты для оценки различных аспектов и показателей, проведена оценка показателей для сравниваемых технологий, на основе чего рассчитан индекс экологичности и качества технологий. 


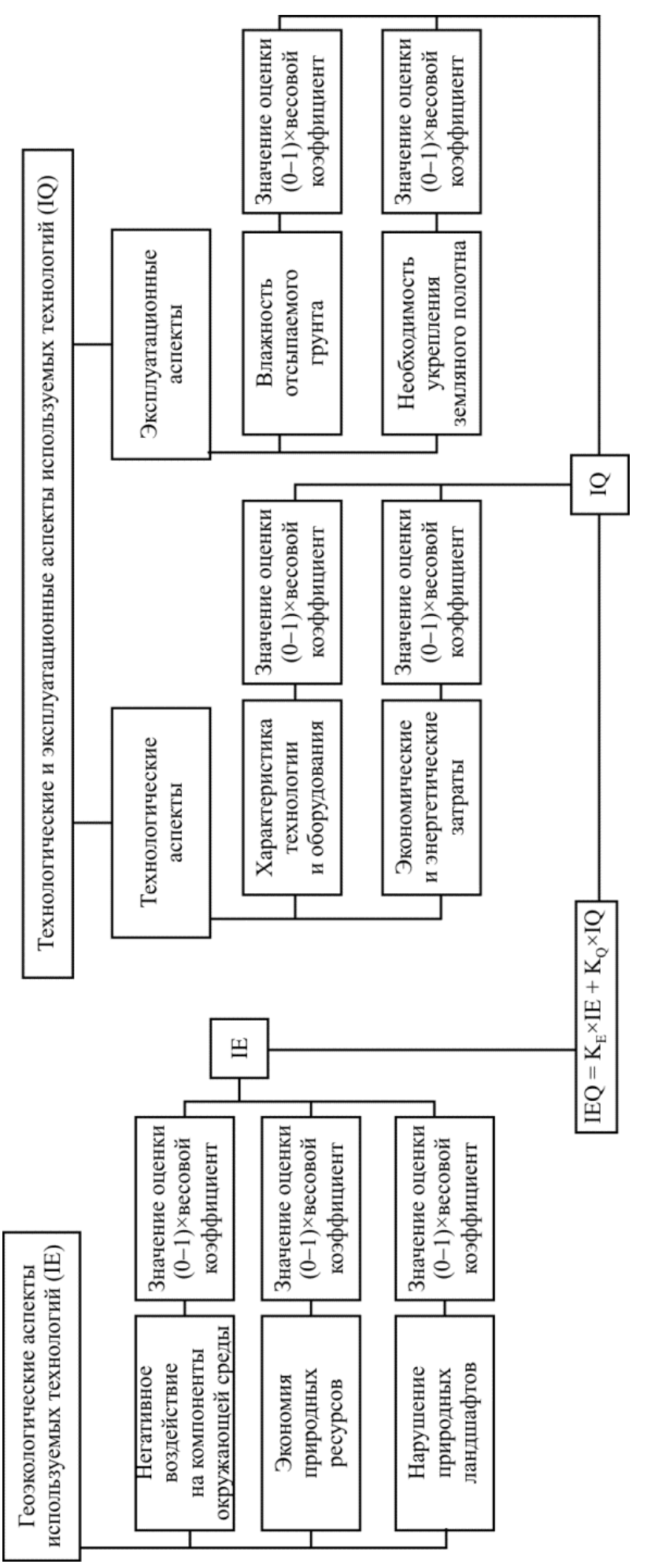

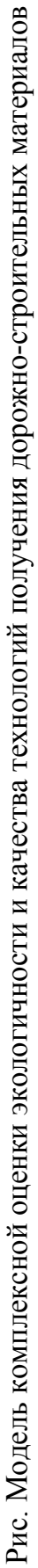


Для аспектов используемых технологий установлены следующие весовые коэффициенты:

геоэкологические аспекты

коэффициент $\mathrm{K}_{\mathrm{E}}=0,4$;

технологические аспекты коэффициент $\mathrm{K}_{\mathrm{Q} 1}=0,3$;

эксплуатационные аспекты коэффициент $\mathrm{K}_{\mathrm{Q} 2}=0,3$.

Для сравниваемых технологий экспертным методом обоснованы следующие весовые коэффициенты:

\section{1. Геоэкологические аспекты:}

показатель 1.1. Негативное воздействие на компоненты окружающей среды - весовой коэффициент 0,5;

показатель 1.2. Экономия природных ресурсов - весовой коэффициент 0,2 ;

показатель 1.3. Нарушение природных ландшафтов - весовой коэффициент 0,3 .

2. Технологические аспекты:

показатель 2.1. Характеристика технологии и оборудования - весовой коэффициент 0,5;

показатель 2.2. Экономические и энергетические затраты - весовой коэффициент 0,5 .

3. Эксплуатационные аспекты:

показатель 3.1. Влажность отсыпаемого грунта - весовой коэффициент 0,5 ;

показатель 3.2. Необходимость укрепления земляного полотна - весовой коэффициент 0,5 .

Проведенная экспертная оценка показала следующие результаты.

1. Геоэкологические аспекты:

Показатель 1.1. При использовании технологии № 1 будет происходить загрязнение компонентов окружающей среды (атмосферного воздуха при карьерном способе добычи, поверхностных водных объектов при добыче речного песка). Основные загрязняющие вещества: пыль, диоксид кремния, взвешенные вещества.

При использовании технологии № 2 будет ликвидировано негативное воздействие на атмосферный воздух, водные объекты и почвы от буровых шламов в местах их размещения; загрязнение окружающей среды при изготовлении шламопесчаных смесей происходит в допустимых пределах.

Экспертная оценка показателя 1.1:

- для технологии № $1-0,3$ (30\%);

- для технологии № $2-0,7$ (70\%). 
Показатель 1.2. При использовании технологии № 1 добывается природный материал - песок, экономия природных ресурсов отсутствует. При использовании технологии № 2 происходит частичная замена природного материала (песка) шламопесчаными смесями - продуктами утилизации буровых шламов.

Экспертная оценка показателя 1.2:

- для технологии № 1 - 0,1 (10\%);

- для технологии № $2-0,9$ (90 \%).

Показатель 1.3. При использовании технологии № 1 происходит образование нарушенных ландшафтов (карьеры от добычи песка). При использовании технологии № 2 ландшафты в процессе изготовления шламопесчаных смесей не нарушаются, благодаря рекультивации шламовых амбаров происходит восстановление нарушенных ландшафтов.

Экспертная оценка показателя 1.3:

- для технологии № 1 - 0,2 (20\%);

- для технологии № $2-0,8(80 \%)$.

2. Технологические аспекты:

Показатель 2.1. Технологический процесс технологии № 1 включает добычу песка спецтехникой на месторождениях и транспортировку его потребителю. Технологический процесс технологии № 2 включает дозирование сырья, смешение его в требуемых соотношениях, сушку полученного материала, очистку отходящих газов, складирование, хранение и транспортировку потребителю готовой продукции.

Экспертная оценка показателя 2.1:

- для технологии № $1-0,9$ (90\%);

- для технологии № $2-0,1(10 \%)$.

Показатель 2.2. При использовании технологии № 1 затраты на реализацию технологии связаны с работой спецтехники и доставкой песка потребителю. При использовании технологии № 2 затраты связаны с капитальными вложениями на строительство и эксплуатацию производства, а также с повышенными энергетическими затратами (сушка смеси).

Экспертная оценка показателя 2.2:

- для технологии № $1-0,9$ (90\%);

- для технологии № $2-0,1(10 \%)$.

3. Эксплуатационные аспекты:

Показатель 3.1. В технологии № 1 используется песок, который является дорожно-строительным материалом с требуемым для строительства набором физико-механических свойств. Значение влажности для пес- 
ков находится в пределах от оптимальной до допустимой влажности 7,2-22,4 \% [20]. В технологии № 2 используются шламопесчаные смеси с требуемым для строительства набором физико-механических свойств. Проведенные исследования смесей показали [15], что их влажность находится в диапазоне 16,5-18,7\%.

Экспертная оценка показателя 3.1:

- для технологии № $1-0,5$ (50\%);

- для технологии № $2-0,5$ (50\%).

Показатель 3.2. В технологии № 1 используется песок. Вследствие малой сопротивляемости размыву дождевой водой и развеиванию ветром земляное полотно из песчаных грунтов необходимо укреплять и уплотнять [21]. В технологии № 2 используется шламопесчаная смесь, представляющая собой супеси или суглинки, которые содержат небольшое количество глинистых частиц, достаточное для придания им связанности в сухом состоянии. При увлажнении эти грунты сохраняют сопротивление нагрузкам, необходимое для устойчивости земляного полотна [21].

Экспертная оценка показателя 3.2:

- для технологии № $1-0,4$ (40\%);

- для технологии № 2 - 0,6 (60\%).

Рассчитанные индексы аспектов используемых технологий:

технология № $1 \quad \mathrm{IE}=0,23, \mathrm{IQ}_{1}=0,9, \mathrm{IQ}_{2}=0,45$;

технология № $2 \quad \mathrm{IE}=0,77, \mathrm{IQ}_{1}=0,1 . \mathrm{IQ}_{2}=0,55$.

Рассчитанный индекс (IEQ):

технология № $1 \quad$ IEQ $=0,497$;

технология № $2 \quad$ IEQ $=0,503$.

Таким образом, применение методики комплексной оценки экологичности и качества технологий позволило выполнить оценку технологии сооружения земляного полотна автодорог с использованием шламопесчаной смеси, изготовленной путем утилизации буровых шламов по экологически безопасной технологии. Показано, что по совокупности геоэкологических, технологических и эксплуатационных аспектов технология сооружения земляного полотна автодорог с использованием шламопесчаных смесей не уступает традиционной, а по геоэкологическим аспектам даже превосходит ее.

\section{Библиографический список}

1. Буровой шлам [Электронный ресурс]. - URL: https://ru.wikipedia.org/wiki/Буровой_шлам (дата обращения: 22.03.2018).

2. Иогансен К.В. Спутник буровика: справ. - 3-е изд., перераб. и доп. - М.: Недра, 1990. - 303 с.

3. Оборудование для утилизации экологически опасных буровых отходов // Сфера Нефтегаз. 2010. - № 2. - C. 114. 
4. Дьяченко Г.П. Внедрение технологии переработки буровых шламов // Экология производства. - 2009. - № 8. - С. 64-68.

5. Скосарева Т.В. Захоронение отходов бурения в подземные резервуары, сооружаемые в многолетнемерзлых породах // Инженерная геология. Гидрогеология. Геокриология. - 1997. - № 1. - С. $44-47$.

6. Пат. 2422218 Рос. Федерация, МПК В09B 5/00, B65D 5/00. Способ подземного захоронения буровых отходов в многолетнемерзлых породах / Гафаров Н.А., Рябоконь А.А., Савич О.И. [и др.]. № 2009148160/21; заявл. 25.12.2009; опубл. 27.06.2011. - 7 с.

7. Thomas Geehan, Alan Gilmour, Quan Guo. The Cutting Edge in Drilling-Waste Management // Oilfield Review. - 2006/2007. - Vol. 18, no. 4. - P. 54-67.

8. Булатов А.И., Макаренко П.П., Шеметов В.Ю. Охрана окружающей среды в нефтегазовой промышленности. - М.: Недра, 1997. - 483 с.

9. Пат. 2199569 Рос. Федерация, МПК С09К7/00, В09С1/08. Смесь для обезвреживания и литификации буровых шламов и нефтезагрязненных грунтов / Кнатько В.М., Кнатько М.В., Гончаров А.В. - № 2001132552/03; заявл. 23.11.2001; опубл. 27.02.2003.

10. Биоремедиация бурового шлама в процессе химической фиксации / Л.Э. Гасымлы [и др.] // Альтернативная энергетика и экология. - 2005.- № 4. - С. 86-90.

11. Пат. 2392256 Рос. Федерация, МПК С05F1/00. Способ обезвреживания отходов бурения нефтяных и газовых скважин / Загидуллин А.Ш., Бородай А.В. - № 2008147085/12; заявл. 01.12.2008; опубл. 20.06.2010. -11 с.

12. Пичугин Е.А. Система управления нефтесодержащими отходами с использованием экологически безопасной технологии их утилизации // Экология и промышленность России. - 2014. № 11. - C. $32-35$.

13. Требования, предъявляемые к шламопесчаным смесям на основе буровых шламов для их применения в качестве экологически чистого строительного дорожного материала / М.В. Зильберман, Е.А. Пичугин, Б.Е. Шенфельд, Г.А. Козлова, В.Л. Долганов // Защита окружающей среды в нефтегазовом комплексе. - 2013. - № 6. - С. 29-34.

14. Пичугин Е.А. Влажность рекультивационных смесей на основе бурового шлама как абиотический экологический фактор // Проблемы региональной экологии. - 2016. - № 4. - С. 80-85.

15. Пичугин Е.А., Шенфельд Б.Е. Оценка физических, прочностных и деформационных характеристик смесей на основе буровых шламов // Экология и промышленность России. - 2015. Т. 19, № 12.- С. 20-24.

16. Оценка распространения загрязняющих веществ в результате использования дорожностроительных материалов на основе буровых шламов при создании оснований дорог / М.В. Зильберман, Е.А. Пичугин, Б.Е. Шенфельд, М.В. Черепанов // Экология урбанизированных территорий. 2014. - № 3. - C. 70-75.

17. Пичугин Е.А., Зильберман М.В., Шенфельд Б.Е. Оценка ассимиляционной емкости экосистемы при размещении в ней дорожно-строительных материалов на основе бурового шлама // Проблемы региональной экологии. - 2014. - № 4. - С. 242-246.

18. Титова Т.С. Методика комплексной оценки экологичности и качества природозащитных технологий, индекс IEQ // Известия ПГУПС. - 2005 - № 2. - С. 98-105.

19. Мархель Н.В., Масленникова Л.Л., Бабак Н.А. Геоэкологическая оценка технологий получения строительных материалов с использованием отходов строительной отрасли // Известия ПГУПС. - 2013. - № 2.- С. 133-141.

20. Попов В. Г. Строительство автомобильных дорог: пособие для мастеров и производителей работ дорожных организаций. - М., 2001.

21. Земляное полотно автомобильной дороги [Электронный ресурc]. - URL: http://markshteter.ru/ sites/default/files/zemlyanoe_polotno_avtodorogi.pdf (дата обращения: 22.03.2018).

\section{References}

1. Burovoy shlam, available at: https://ru.wikipedia.org/wiki/Burovoy_shlam (accessed 22 March 2018).

2. Iogansen K.V. Sputnik burovika [Driller's handbook]: Spravochnik. 3-e izd. pererab. i dop. Moscow, Nedra, 1990. 303 p. 
3. Oborudovaniye dlya utilizatsii ekologicheski opasnykh burovykh otkhodov [Equipment for utilization of environmentally hazardous drilling waste]. Sfera Neftegaz, 2010, no. 2, pp. 114.

4. Diachenko G.P. Vnedreniye tekhnologii pererabotki burovykh shlamov [Introduction of technology of processing of drill cuttings]. Ecology of production, 2009, no. 8, pp. 64-68.

5. Skosareva T.V. Zakhoroneniye otkhodov bureniya $\mathrm{v}$ podzemnyye rezervuary. sooruzhayemyye $\mathrm{v}$ mnogoletnemerzlykh porodakh [Burial of drilling wastes in underground reservoirs constructed in permafrost]. Engineering geology. Hydrogeology. Geocryology, 1997, no. 1, pp. 44-47.

6. Gafarov N.A., Ryabokon A.A., Savich O.I. et al. Sposob podzemnogo zakhoroneniya burovykh otkhodov v mnogoletnemerzlykh porodakh [Method of underground burial of drilling waste in permafrost]. Patent Rossiyskaya Federatsiya no. 2009148160/21 (2011).

7. Thomas Geehan, Alan Gilmour, Quan Guo. The Cutting Edge in Drilling-Waste Management. Oilfield Review, 2006/2007, vol. 18, no. 4, pp. 54-67.

8. Bulatov A.I., Makarenko P.P., Shemetov V.Yu. Okhrana okruzhayushchey sredy v neftegazovoy promyshlennosti [Environmental protection in the oil and gas industry]. Moscow, Nedra, 1992, $483 \mathrm{p}$.

9. Knatko V.M., Knatko M.V., Goncharov A.V. Smes dlya obezvrezhivaniya i litifikatsii burovykh shlamov i neftezagryaznennykh gruntov [The mixture for neutralization and lithification drilling sludge and oil-contaminated soil]. Patent Rossiyskaya Federatsiya no. 2001132552/03 (2003).

10. Gasymly L.E. et al. Bioremediatsiya burovogo shlama $\mathrm{v}$ protsesse khimicheskoy fiksatsii [Bioremediation of drill cuttings in the process of chemical fixation]. Alternative Energy and Ecology, 2005, no. 4, pp. 86-90.

11. Zagidullin A.Sh., Boroday A.V. Sposob obezvrezhivaniya otkhodov bureniya neftyanykh i gazovykh skvazhin [The method of neutralizing oil and gas wells drilling waste]. Patent Rossiyskaya Federatsiya no. 2008147085/12 (2010).

12. Pichugin E.A. Sistema upravleniya neftesoderzhashchimi otkhodami $\mathrm{s}$ ispolzovaniyem ekologicheski bezopasnoy tekhnologii ikh utilizatsii [The control system for oil-containing wastes with the use of environmentally safe technology for their utilization]. Ecology and industry of Russia, 2014, no. 11, pp. 32-35.

13. Zilberman M.V., Pichugin E.A., Shenfeld B.E., Kozlova G.A., Dolganov V.L. Trebovaniya. predyavlyayemyye $\mathrm{k}$ shlamo-peschanym smesyam na osnove burovykh shlamov dlya ikh primeneniya $\mathrm{v}$ kachestve ekologicheski chistogo stroitelnogo dorozhnogo materiala [Requirements for slurry-sand mixtures based on drilling mud for their use as environmentally friendly construction road material]. Zashchita okruzhayushchey sredy v neftegazovom komplekse, 2013, no 6, pp. 29-34.

14. Pichugin E.A. Vlazhnost rekultivatsionnykh smesey na osnove burovogo shlama kak abioticheskiy ekologicheskiy faktor [Humidity of recultivation mixtures based on drill cuttings as abiotic ecological factor]. Problems of regional ecology, 2016, no. 4, pp. 80-85.

15. Pichugin E.A., Shenfeld B.E. Otsenka fizicheskikh. prochnostnykh i deformatsionnykh kharakteristik smesey na osnove burovykh shlamov [Evaluation of physical, strength and deformation characteristics of mixtures based on drill cuttings]. Ecology and industry of Russia, 2015, vol. 19, no. 12, pp. 20-24.

16. Zilberman M.V., Pichugin E.A., Shenfeld B.E., Cherepanov M.V. Otsenka rasprostraneniya zagryaznyayushchikh veshchestv $\mathrm{v}$ rezultate ispolzovaniya dorozhno-stroitelnykh materialov na osnove burovykh shlamov pri sozdanii osnovaniy dorog [Assessment of the spread of pollutants as a result of the use of road-building materials based on drill cuttings when creating the foundations of roads]. Ekologiya urbanizirovannykh territoriy, 2014, no. 3, pp. 70-75.

17. Pichugin E.A., Zilberman M.V., Shenfeld B.E. Otsenka assimilyatsionnoy emkosti ekosistemy pri razmeshchenii $\mathrm{v}$ ney dorozhno-stroitelnykh materialov na osnove burovogo shlama [Estimation of the ecosystem's assimilation capacity by placing in it road-building materials based on drill cuttings]. Problems of regional ecology, 2014, no. 4, pp. 242-246.

18. Titova T.S. Metodika kompleksnoy otsenki ekologichnosti i kachestva prirodozashchitnykh tekhnologiy. indeks IEQ [Methodology of comprehensive environmental evaluation and quality prirodozaschitnyh technology index IEQ]. Proceedings of Petersburg Transport University, 2005, no. 2, pp. 98-105. 
19. Markhel N.V., Maslennikova L.L., Babak N.A. Geoekologicheskaya otsenka tekhnologiy polucheniya stroitelnykh materialov $\mathrm{s}$ ispolzovaniyem otkhodov stroitelnoy otrasli [Geoecological assessment of technologies for obtaining building materials using waste from the construction industry]. Proceedings of Petersburg Transport University, 2013, no 2, pp. 133-141.

20. Popov V.G. Ctroitelstvo avtomobilnykh dorog [Construction of motor roads]. Posobiye dlya masterov i proizvoditeley rabot dorozhnykh organizatsiy. Moscow, 2001.

21. Zemlyanoye polotno avtomobilnoy dorogi, available at: http://markshteter.ru/sites/default/files/ zemlyanoe_polotno_avtodorogi.pdf(accessed 10 March 2018).

Получено 27.03.2018

\author{
E. Pichugin, B. Shenfeld, A. Ketov
}

\title{
COMPREHENSIVE ASSESSMENT OF ENVIRONMENTAL COMPATIBILITY AND QUALITY OF ROAD BED CONSTRUCTION WITH THE USE OF SLUDGE-SAND MIXTURE - THE PRODUCT OF WASTE RECYCLING
}

When drilling oil and gas wells, drilling sludge is formed, representing toxic drilling waste mainly located in sludge pits, which have a negative impact on the lithosphere. The impact is due to the withdrawal of lands from turnover, cutting down trees and shrubs, eroding the overlying cover, insufficient waterproofing of the sludge pits during their construction and operation, and using reclamation technologies that do not meet environmental protection requirements. A promising direction of the disposal of drilling sludge is its recycling by creating on its basis construction materials that do not have a negative impact on the environment and are suitable for use along with traditional ones. Using the methodology of integrated assessment of environmental compatibility and quality of environmental technologies, an assessment was made of technologies for constructing roadbeds of motor roads, including using sludge-sand mixtures based on oil and gas drilling waste (drill cuttings). Formed in accordance with the methodology, the IEQ index characterizes the environmental compatibility and quality of the technology. For the assessment, a model is constructed that allows assessing environmental technologies for geo-ecological, technological and operational aspects. To evaluate each aspect, an integral method was used, which consists in the fact that the technological process and the technogenic impact are considered within a rating scale. The scores were formed on the basis of expert assessments. For each aspect, the advantages and disadvantages of the presented environmental technologies are shown. The experts have selected weighting factors to assess various aspects and indicators, an assessment of indicators for the compared technologies was conducted, based on which the index of environmental compatibility and quality of every technology was calculated. On the basis of the expert integrated assessment it was shown that the technology of construction of the roadbed with the use of sludge-sand mixtures is not inferior to the traditional on the totality of geo-ecological, technological and operational aspects.

Keywords: earth roadbed, waste recycling, drill cuttings, sludge-sand mixture, environmental compatibility and quality assessment.

Пичугин Евгений Александрович (Пермь, Россия) - заместитель начальника отдела проблем охраны окружающей среды, Уральский государственный научно-исследовательский институт региональных экологических проблем (ФГБУ УралНИИ «Экология») (614039, г. Пермь, Комсомольский пр., 61a, e-mail: pich@ecology.perm.ru). 
Шенфельд Борис Евгеньевич (Пермь, Россия) - д-р техн. наук, профессор, научный руководитель, Уральский государственный научно-исследовательский институт региональных экологических проблем (ФГБУ УралНИИ «Экология») (614039, г. Пермь, Комсомольский пр., 61a, e-mail: shenfeld@ecology.perm.ru).

Кетов Александр Анатольевич (Пермь, Россия) - д-р техн. наук, профессор кафедры неорганической химии Пермского государственного национального исследовательского университета (614990, г. Пермь, ул. Букирева, 15, e-mail: alexander_ketov@mail.ru).

Pichugin Evgeniy (Perm, Russian Federation) - Deputy head of the Department of Environmental Protection of the Federal State Budgetary Institution "Ural State Scientific Research Institute of Regional Environmental Problems" (FGBU UralNII "Ecology") (614039, Perm, Komsomolsky av., 61a, e-mail: pich@ecology.perm.ru).

Shenfeld Boris (Perm, Russian Federation) - Doctor of Technical Sciences, Professor, Scientific Director of the Federal State Budgetary Institution "Ural State Scientific Research Institute of Regional Environmental Problems" (FGBU UralNII "Ecology") (614039, Perm, Komsomolsky av., 61a, e-mail: shenfeld@ecology.perm.ru).

Ketov Alexander (Perm, Russian Federation) - Doctor of Technical Sciences, Professor of the Department of Inorganic Chemistry, Perm State National Research University (614990, Perm, Bukirev str., 15, e-mail: alexander_ketov@mail.ru). 